\title{
Is routine performance of the uterine cervix canal curettage prior to the curettage of the uterine cavity justified?
}

\author{
Szymon Piątek, Jacek Lipa, Monika Górska, Katarzyna Malecha, \\ Grzegorz Panek, Mirosław Wielgoś \\ $1^{\text {st }}$ Department of Obstetrics and Gynecology, Medical University of Warsaw, Poland
}

\begin{abstract}
Objectives: Endocervical curettage (ECC) together with the dilatation and curettage of the uterine cavity $(D \& C)$ is routinely performed in everyday clinical practice. The aim of this study is to assess the rationale of the performance of ECC prior to $D \& C$ in indications other than abnormal uterine bleeding (AUB).
\end{abstract}

Material and methods: Case histories of 736 patients after ECC performed in the $1^{\text {st }}$ Department of Obstetrics and Gynaecology, Medical University of Warsaw, were analyzed retrospectively, the indications for the procedure - age, menopausal status, parity, procedure operator's experience - as well as the result of the histopathology examination were taken into account. Three groups of patients were distinguished based on the indications for the procedure.

Results: In 645 (87.6\%) of cases normal histopathology results were obtained. 40 (5.4\%) cases were abnormal. 31 cases of uterine cervix dysplasia were disclosed (CIN 1-20; CIN 2-5; CIN 3-6), 8 cases of endometrial cancer and 1 case of cancer of the uterine cervix were disclosed. In 51 (7\%) of cases tissue material for histopathology examination was not obtained. In patients where ECC and D \& C were performed due to indications other than abnormal bleeding from uterine cavity, no abnormal results were revealed. In addition, in this group the highest number of non-diagnostic ECCs was reported (11.59\%; $\mathrm{p}<0.05)$.

Conclusions: In the case of endometrial biopsy for indications other than AUB routine ECC prior to D \& C need not be performed.

Key words: endocervical curettage, dilatation and curettage, endometrial biopsy

Ginekologia Polska 2017; 88, 9: 463-468

\section{INTRODUCTION}

The curettage of the uterine cervix canal (endocervical curettage, ECC) is a procedure allowing to sample tissue material for histopathology examination. It is considered by many gynaecologists to be an indispensable element of the colposcopic assessment allowing to exclude non-symptomatic cases of dysplasia/cancer of the uterine cervix and should be performed in all non-pregnant women, irrespective of age or cytology result [1, 2]. A routine ECC during colposcopy (irrespective of its result) increases its sensitivity. It was pointed out that 2-6\% of high-grade dysplasia as well as uterine cervix cancer are detected solely thanks to the
ECC $[3,4]$. According to some authors ECC should be performed only in case of abnormal cytology results or unsatisfactory colposcopy [5, 7].

In spite of the broad application of outpatient techniques of endometrial biopsy, dilatation and curettage of the uterine cavity ( $D \& C$ ) in numerous situations remains the principal diagnostic method [8]. In everyday clinical practice $D \& C$ is routinely performed together with ECC. The advantage of $D \& C$ over other less invasive methods of endometrial biopsy (Pipella, tao brush, vacuum biopsy) is often emphasized, the possibility of a simultaneous sampling of material from the uterine cervix canal being 
indicated. Indications for D \& C and ECC include abnormal uterine bleeding (AUB), an abnormal picture of the endometrium on USG examination, a suspicion of an endometrial polyp, check-ups after endometrial hyperplasia treatment as well as non-diagnostic biopsies with low-invasive techniques. While in the case of abnormal bleedings from the birth canal a combined performance of ECC and D \& C arouses no doubts, routine ECC during D \& $C$ in the case of other indications remains a controversial procedure.

\section{OBJECTIVES}

The aim of the study is the assessment of the rationale of the performance of ECC prior to $D \& C$ in the case of indications other than abnormal bleedings.

\section{MATERIAL AND METHODS}

Case histories of 736 patients after ECC performed in the $1^{\text {st }}$ Department of Obstetrics and Gynaecology, Medical University of Warsaw, between January 2002 and November 2004 were analyzed retrospectively. Based on the indications for the ECC procedure, the patients were divided into three groups. In 287 of cases the indication for ECC was a suspicion of cervical dysplasia including an abnormal cytology result (ASC-US, ASC-H, L-SIL, H-SIL) or unsatisfactory/abnormal colposcopy. The second group covered 285 women in whom ECC was performed together with D \& C due to abnormal bleedings from the uterine cavity. The last group were 164 women in whom ECC together with D \& C was performed for reasons other than abnormal bleedings from the birth canal i.e.: an abnormal picture of the endometrium on USG examination, a suspicion of an endometrial polyp, check-up after endometrial hyperplasia treatment or non-diagnostic endometrial biopsies with low-invasive techniques.

An analysis was conducted of the following factors of potential influence on obtaining adequate histopathology material: age, menopausal status, parity and experience of the procedure-performing operator.

The mean age of patients covered by the study was 49.87 yrs (18-86 yrs). Post-menopausal women and menstruating women constituted $41.44 \%$ (305/736) and 58.66\% $(431 / 736)$, respectively. The study population included $20.92 \%$ (152/736) of nulliparas. 12 doctors in the course of specialty training performed $61 \%(449 / 736)$ of the procedures. The remaining procedures, i.e. 39\% (287/736), were performed by 10 specialists in the field of obstetrics and gynaecology. A detailed characteristics of the study groups of women is given in Table 1.

\section{Examination technique}

ECC was performed with the use of sharp metal, size \#2 curettes. Prior to the commencement of the procedure sterile swabs were placed in the lower speculum so as not to lose small scrapings from the uterine cervix canal. The anterior lip of the uterine cervix was captured with a vulsella and pulled downwards. Next, each of the four quadrants of the canal were scraped out. In the case of patients undergoing endometrial sampling, ECC was always performed before $D \& C$ to prevent mixing up specimen from the uterine cavity with the tissue from the cervical canal.

The following abnormal histopathology results were revealed on ECC: dysplasia of the uterine cervix, cervical cancer, endometrial cancer. The normal results were adopted to include: normal texture of the mucous membrane of the uterine cervix canal, metaplasia of the epithelium of the uterine cervix canal, inflammation of the uterine cervix canal.

The statistical analysis was conducted in Statistica 12 software. In the analysis of measurable data student t-test was used, in the absence of normality the Mann-Whitney $U$ test was used. To evaluate the dependence of qualitative variables chi-square test was used. A statistical significance level of 0.05 was adopted.

Table 1. Characteristics and comparison of analyzed groups

\begin{tabular}{|c|c|c|c|c|c|c|}
\hline Groups & Indications for ECC & $\begin{array}{l}\text { Number of } \\
\text { women } \\
\text { (all } n=736)\end{array}$ & Mean age & $\begin{array}{c}\text { Post-menopausal } \\
\text { women }\end{array}$ & Nulliparas & $\begin{array}{l}\text { Procedures performed by } \\
\text { doctors in the course of } \\
\text { training }\end{array}$ \\
\hline Group No. 1 & $\begin{array}{l}\text { Other than abnormal } \\
\text { bleedings } \\
\text { (together with } \mathrm{D} \& \mathrm{C} \text { ) }\end{array}$ & 164 & $56.79(26-86)$ & $107(65 \%)$ & $26(15.85 \%)$ & $103(62.8 \%)$ \\
\hline Group No. 2 & $\begin{array}{l}\text { Abnormal bleedings } \\
\text { (together with } D \& C \text { ) }\end{array}$ & 285 & $51.21(23-86)$ & $136(47.7 \%)$ & $46(16.19 \%)$ & $183(64 \%)$ \\
\hline Group No. 3 & $\begin{array}{l}\text { Suspicion of uterine } \\
\text { cervix dysplasia }\end{array}$ & 287 & $41.61(18-75)$ & $62(21.6 \%)$ & $82(28.57 \%)$ & $163(56 \%)$ \\
\hline \multicolumn{3}{|c|}{$\begin{array}{l}\text { Statistical difference between groups in analyzed } \\
\text { variables (age, menopausal status, parity, doctor's } \\
\text { experience) }\end{array}$} & $p<0.05$ & $p<0.05$ & $p<0.05$ & $p>0.05$ \\
\hline
\end{tabular}




\section{RESULTS}

40 (5.4\%) out of the 736 results of scrapings from the uterine cervix canal were abnormal. 31 cases of uterine cervix dysplasia (CIN 1-20; CIN 2-5; CIN 3-6), 8 cases of endometrial cancer and 1 case of uterine cervix cancer were disclosed. In 645 (87.6\%) of cases normal histopathology results were obtained: (538 - normal mucous membrane of the uterine cervix canal, 68 - metaplasia of the uterine cervix canal; 39 - inflammation of epithelium of the uterine cervix canal). In 51 (7\%) of cases no tissue material was obtained for histopathology examination (mucus, blood). Table 2 presents the results of the histopathology examination of scrapings from the uterine cervix canal according to indications for ECC.

Almost all diagnoses of uterine cervix dysplasia (29/31; 93.55\%) were obtained in the group of women in which a suspicion of cervical intraepithelial neoplasia was an indication for ECC (Figure 1). Two cases of uterine cervix dysplasia were diagnosed in the course of procedures performed due to abnormal bleedings from the birth canal with simultaneous normal results from uterine cavity scrapings. The only case of an invasive uterine cervix cancer was reported in the group with a suspicion of uterine cervix dysplasia.

8 cases of endometrial cancel were disclosed in scrapings from the uterine cervix canal. In all these cases the indication for the procedure involved abnormal bleedings from the birth canal. In 7 of them identical cells were present in the scrapings from the uterine cavity. In one case, abrasion of the uterine cavity revealed purulent and atrophic foci without neoplastic cells. In this case, the diagnosis of endometrial cancer was based on ECC.

Scrapings from the uterine cervix canal in the group of women subjected to ECC for indications other than AUB did not produce any abnormal histopathology results.

A statistically significant difference was found between the analyzed patient groups in terms of the frequency of failure to obtain material from the uterine cervix canal $(p<0.05)$. The highest number of non-diagnostic biopsies was registered among patients who underwent ECC together with $D$ \& $C$ from indications other than abnormal bleedings from the birth canal - 19/164 (11.59\%). Fewer non-diagnostic biopsies were performed in the group of patients with abnormal bleedings from the birth canal $-23 / 285(8.07 \%)$ as well as in patients with a suspicion of uterine cervix dysplasia 9/287 (3.14\%).

The age of the patients proved to be a factor of essential influence on obtaining diagnostic material in all groups. Simultaneously, the menopausal status and the experience of the doctor performing the procedure were essential factors in women with a suspicion of dysplasia as well as in patients

Table 2. Abnormal histopathological results

\begin{tabular}{|c|c|c|c|c|c|}
\hline Groups & Indications for ECC & $\begin{array}{l}\text { Dysplasia } \\
(n=31)\end{array}$ & $\begin{array}{l}\text { Uterine cervix } \\
\text { cancer }(n=1)\end{array}$ & $\begin{array}{l}\text { Endometrial } \\
\text { cancer }(\mathbf{n}=\mathbf{8})\end{array}$ & $\begin{array}{l}\text { Absence } \\
\text { of material }\end{array}$ \\
\hline $\begin{array}{l}\text { Group No. } 1 \\
(n=164)\end{array}$ & $\begin{array}{l}\text { Other than abnormal bleedings } \\
\text { (together with } D \& C \text { ) }\end{array}$ & 0 & 0 & 0 & $19(11.59 \%)$ \\
\hline $\begin{array}{l}\text { Group No. } 2 \\
(n=285)\end{array}$ & $\begin{array}{l}\text { Abnormal bleedings } \\
\text { (together with } D \& C \text { ) }\end{array}$ & $2(0.7 \%)$ & 0 & $8(2.8 \%)$ & $23(8.07 \%)$ \\
\hline $\begin{array}{l}\text { Group No. } 3 \\
(n=287)\end{array}$ & Suspicion of uterine cervix dysplasia & $29(10.45 \%)$ & $1(0.3 \%)$ & 0 & $9(3.14 \%)$ \\
\hline
\end{tabular}

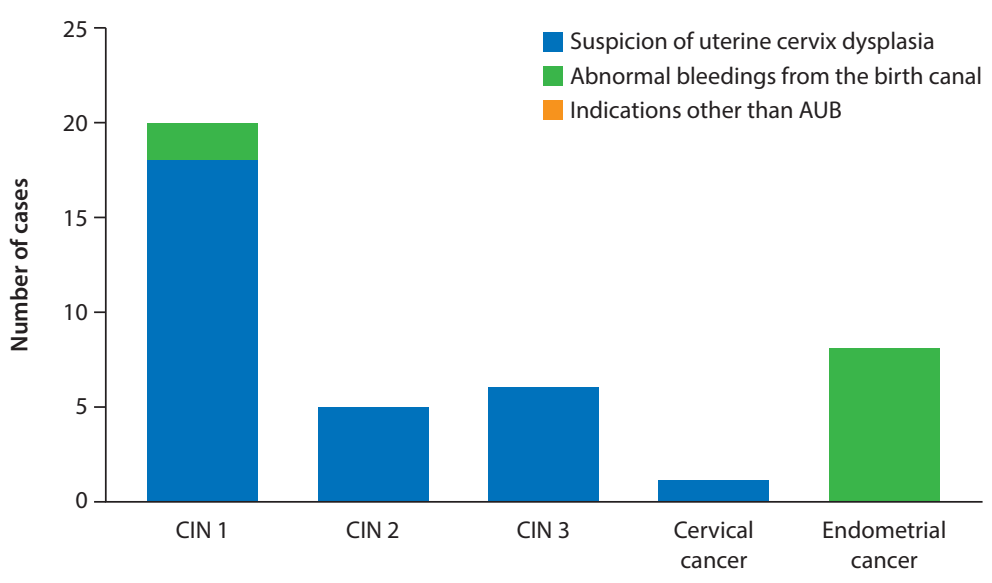

Figure 1. Abnormal histopathological results 
Table 3. Comparison of diagnostic ECC vs. non-diagnostic ECC

\begin{tabular}{|c|c|c|c|c|}
\hline Group & Variables & Diagnostic ECC & $\begin{array}{l}\text { Non-diagnostic } \\
\text { ECC }\end{array}$ & $\begin{array}{l}\text { Statistical } \\
\text { significance }\end{array}$ \\
\hline \multirow{4}{*}{$\begin{array}{l}\text { Indications other } \\
\text { than AUB }\end{array}$} & Mean age & 55.5 & 59 & $p<0.05$ \\
\hline & Post-menopausal women & $94 / 145(64.8 \%)$ & $12 / 19(63 \%)$ & $p>0.05$ \\
\hline & $\begin{array}{l}\text { Procedures performed by doctors in the course of } \\
\text { training }\end{array}$ & $92 / 145(63.4 \%)$ & $13 / 19(68 \%)$ & $p>0.05$ \\
\hline & Nulliparas & 26/145 (17.93\%) & 0 & $p<0.05$ \\
\hline \multirow{4}{*}{ AUB } & Mean age & 50,5 & 59 & $p<0.05$ \\
\hline & Post-menopausal women & $118 / 262(45.04 \%)$ & 18/23 (78.26\%) & $p<0.05$ \\
\hline & $\begin{array}{l}\text { Procedures performed by doctors in the course of } \\
\text { training }\end{array}$ & $165 / 262(62.98 \%)$ & 18/23 (78.26\%) & $p<0.05$ \\
\hline & Nulliparas & 43/262 (16.41\%) & $3 / 23(13.04 \%)$ & $p>0.05$ \\
\hline \multirow{4}{*}{$\begin{array}{l}\text { Dysplasia of the } \\
\text { uterine cervix }\end{array}$} & Mean age & 39.9 & 48.5 & $p<0.05$ \\
\hline & Post-menopausal women & $69 / 278(24.82 \%)$ & $6 / 9(66.66 \%)$ & $p<0.05$ \\
\hline & $\begin{array}{l}\text { Procedures performed by doctors in the course of } \\
\text { training }\end{array}$ & $159 / 278(57.19 \%)$ & $5 / 9(55.55 \%)$ & $p>0.05$ \\
\hline & Nulliparas & $79 / 278(28.41 \%)$ & $3 / 9(33.33 \%)$ & $p>0.05$ \\
\hline
\end{tabular}

with abnormal bleedings from the birth canal. No relation was found between absence of a history of past labours and a higher percentage of non-diagnostic biopsies (Table 3).

\section{DISCUSSION}

ECC is used first and foremost in the diagnosis of dysplasia of the epithelium of the uterine cervix canal and abnormal bleedings from the birth canal. However, in everyday clinical practice this procedure is very often performed together with $D \&$ C regardless of the presence of a suspicion of a pathology within the uterine cervix canal. A variety of reasons have been given in support of this approach.

Firstly, it is argued that the sensitivity of cytological smears in the detection of uterine cervix dysplasia is unsatisfactory. Older publications estimate the sensitivity and specificity of cytology at $80-94 \%$ and $99 \%$, respectively $[9,10]$. In a Canadian study covering over 10000 of women, the sensitivity of cytology was reported to be $55.4 \%$, with a specificity of $96.8 \%$ [11]. Studies conducted over the past few years indicate a sensitivity of $57-58 \%$ and specificity of $63-76 \%[12,13]$. In one of the largest studies dealing with the primary prophylaxis of cancer of the uterine cervix carried out in North America and Europe, over 60000 women were examined and the sensitivity and specificity of cytology were estimated at $53 \%$ and $96.3 \%$, respectively [14]. Numerous studies assessed also the sensitivity and specificity of ECC. It amounts to $49-82 \%$ and $75-97 \%$, respectively [15-18]. What is also indicated is a high percentage of false negative and false positive results of ECC amounting to $45 \%$ and $25 \%$, respectively [15]. A direct comparison was also made of ECC with cytology in a follow-up in women after the treatment of uterine cervix dysplasia which revealed the superiority of cytology $[1,19]$. ASCCP recommendations with respect to the collection of material from the uterine cervix canal include both the brush and the traditional biopsy (ECC) [20]. Attention was however drawn to the higher sensitivity with similar specificity, better tolerance as well as lower percentage of non-diagnostic attempts obtained with the use of the brush technique.

The unsatisfactory quality of cytology can result from the absence of endocervix cells in the smear. It was found out that abnormal results were more common in smears containing endocervix cells than in smears without endocervix cells [21, 22]. Following these studies, the assessment of endocervix cells became a standard as it was believed to increase the chance of detecting abnormalities. Yet, later studies failed to prove that the presence of endocervix cells guarantees the detection of abnormalities [23-26]. A large study covering approximately 50000 patients showed that absence of endocervix cells in a smear is not linked to an increased risk of abnormalities in subsequent smears [26]. These results tend to be explained with a thesis that abnormal cells in the cervical canal are more weakly attached to the matrix and thus easier to be sampled. Consequently, the performance of ECC in the absence of endocervix cells in normal cytological smears is unjustified.

Secondly, in countries with a low percentage of women having cytology regularly (in Poland, in the years 2007-2009, only $24 \%$ of women took part in the uterine cervix cancer prophylaxis programme [27]), ECC might be treated as an element of screening for uterine cervix cancer increasing the number of women under oncologic monitoring and giving a chance to detect abnormalities within the canal epithelium. However, ECC alone does not give a complete picture of the condition 
of the uterine cervix and cannot be treated as a substitute of cytology. A normal result can give the patient a feeling of false security simultaneously encouraging the gynaecologist to resign from the performance of a check-up cytology.

The performance of ECC together with D \& C can also result from the fear of a possible presence of an occult (asymptomatic) cancer of the uterine cervix. Yet, the sensitivity of ECC in the detection of abnormalities within both the squamous and the glandular epithelium is too low. Andersen et al. showed that ECC fails to detect $45 \%$ of changes in the squamous epithelium present in the cervical canal [15]. In turn, two studies evaluating ECC in terms of the detection of abnormal changes in the glandular epithelium sensitivity were found to be at the level of $43 \%$ and $35 \%[28,29]$. Irvin et al. proved that failure to perform ECC in women with an abnormal cytology result will not result in failure to diagnose an invasive or micro-invasive cancer of the uterine cervix. Moreover, in this study, the only case of an invasive cancer of the uterine cervix was detected in a patient with a normal ECC result [30].

Abnormal bleedings from the birth canal, in particular in post-menopausal women, can be the first sign of endometrial cancer [31]. In menstruating women, they can be indicative of dysplasia/cancer of the uterine cervix [32]. Therefore, in the case of abnormal bleedings from the birth canal, ECC should always be performed together with D \& C. Our study also confirms the necessity of performing ECC together with $D \&$ \& in the case of abnormal bleedings from the birth canal. In 2 cases abnormal bleedings were caused by dysplasia of the epithelium of the uterine cervix canal.

What deserves particular attention, however, is one of the cases of endometrial cancer. The material sampled from the uterine cavity contained purulent and atrophic foci without cancer cells while tumour tissue texture was present only in the scrapings from the uterine cervix canal. Failure to perform ECC in this case would at best have caused a delay in diagnosis and at worst it could have resulted in missing the presence of endometrial cancer.

The performance of ECC together with $D \& C$ in the case of indications other than abnormal bleedings from the birth canal is a controversial procedure. This results also from our study. In 164 cases not a single abnormal result was found. What was reported, however, was the highest percentage of non-diagnostic biopsies. Other works showed that in $2.5-28 \%$ of cases ECC fails to produce diagnosis due to too small or inadequate material for histopathology examination [15-17, 33]. The main drawback of this procedure seems to be the high percentage of non-diagnostic results.

The principal limitation of the present study is its retrospective character as well as the relatively small size of the study group. In order to formulate unequivocal recommen- dations it is necessary to conduct a prospective study with significantly more numerous groups of women selected in terms of age and menopausal status. Simultaneously, to confirm the impact of the experience of the ECC-performing doctor a randomized assignment of a doctor to a patient should be made.

\section{CONCLUSIONS}

ECC is the gold standard in the diagnostics of endocervix pathologies. Routine performance of ECC prior to $D \& C$ is justified primarily in the diagnostics of abnormal bleedings from the birth canal. Simultaneously, in the case of endometrial biopsy due to indications other than AUB, ECC need not be performed prior to $D \& C$, in particular in post-menopausal patients and in patients with a non-contributory cytological history.

The efficacy of ECC in obtaining tissue material depends on indications for the procedure and the age of the patient. Additional factors of potential influence on ECC include: parity, menopausal status and experience of the procedure-performing doctor.

\section{REFERENCES}

1. Moniak CW, Kutzner S, Adam E, et al. Endocervical curettage in evaluating abnormal cervical cytology. J Reprod Med. 2000; 45(4): 285-292, indexed in Pubmed: 10804483.

2. Soisson AP, Molina CY, Benson WL. Endocervical curettage in the evaluation of cervical disease in patients with adequate colposcopy. Obstet Gynecol. 1988; 71(1): 109-111, indexed in Pubmed: 3336531.

3. Solomon D, Stoler M, Jeronimo J, et al. Diagnostic utility of endocervical curettage in women undergoing colposcopy for equivocal or low-grade cytologic abnormalities. Obstet Gynecol. 2007; 110 (2 Pt 1):288-295, doi: 10.1097/01.AOG.0000270154.69879.09, indexed in Pubmed: 17666602.

4. Pretorius RG, Zhang WH, Belinson JL, et al. Colposcopically directed biopsy, random cervical biopsy, and endocervical curettage in the diagnosis of cervical intraepithelial neoplasia II or worse. Am J Obstet Gynecol. 2004; 191(2):430-434, doi: 10.1016/j.ajog.2004.02.065, indexed in Pubmed: 15343217.

5. Massad LS, Einstein MH, Huh WK, et al. 2012 ASCCP Consensus Guidelines Conference, 2012 ASCCP Consensus Guidelines Conference. 2012 updated consensus guidelines for the management of abnormal cervical cancer screening tests and cancer precursors. J Low Genit Tract Dis. 2013; 17(5 Suppl 1): S1-S27, doi: 10.1097/LGT.0b013e318287d329, indexed in Pubmed: 23519301.

6. Nasierowska-Guttmejer A, Kędzia W, Wojtylak S, et al. Polish recommendations regarding diagnostics and treatment of cervical squamous intraepithelial lesions according to the CAP/ASCCP guidelines. Ginekol Pol. 2016; 87(9): 676-682, doi: 10.5603/GP.2016.0066, indexed in Pubmed: 27723078.

7. Oyer R, Hanjani P. Endocervical curettage: does it contribute to the management of patients with abnormal cervical cytology? Gynecol Oncol. 1986; 25(2): 204-211, indexed in Pubmed: 3758830.

8. Piątek S, Panek G, Wielgoś M. Assessment of the usefulness of pipelle biopsy in gynecological diagnostics. Ginekol Pol. 2016; 87(8): 559-564, doi: 10.5603/GP.2016.0044, indexed in Pubmed: 27629129.

9. Soost HJ, Lange HJ, Lehmacher W, et al. The validation of cervical cytology. Sensitivity, specificity and predictive values. Acta Cytol. 1991; 35(1): 8-14, indexed in Pubmed: 1994641.

10. van der Graaf Y, Vooijs GP. False negative rate in cervical cytology. J Clin Pathol. 1987; 40(4): 438-442, indexed in Pubmed: 3584488.

11. Mayrand MH, Duarte-Franco E, Rodrigues I, et al. Canadian Cervical Cancer Screening Trial Study Group. Human papillomavirus DNA versus Papanicolaou screening tests for cervical cancer. N Engl J Med. 
2007; 357(16): 1579-1588, doi: 10.1056/NEJMoa071430, indexed in Pubmed: 17942871.

12. Rokita W, Kedzia W, Pruski D, et al. [The diagnostic value of cytology and colposcopy in women with cervical intraepithelial neoplasia]. Ginekol Pol. 2011; 82(8): 607-611, indexed in Pubmed: 21957606.

13. Barut MU, Kale A, Kuyumcuoğlu U, et al. Analysis of Sensitivity, Specificity, and Positive and Negative Predictive Values of Smear and Colposcopy in Diagnosis of Premalignant and Malignant Cervical Lesions. Med Sci Monit. 2015; 21: 3860-3867, indexed in Pubmed: 26655816.

14. Cuzick J, Clavel C, Petry KU, et al. Overview of the European and North American studies on HPV testing in primary cervical cancer screening. Int J Cancer. 2006; 119(5): 1095-1101, doi: 10.1002/ijc.21955, indexed in Pubmed: 16586444.

15. Andersen $W$, Frierson $H$, Barber $S$, et al. Sensitivity and specificity of endocervical curettage and the endocervical brush for the evaluation of the endocervical canal. Am J Obstet Gynecol. 1988; 159(3): 702-707, indexed in Pubmed: 3048105.

16. Mogensen ST, Bak M, Dueholm M, et al. Cytobrush and endocervical curettage in the diagnosis of dysplasia and malignancy of the uterine cervix. Acta Obstet Gynecol Scand. 1997; 76(1): 69-73, indexed in Pubmed: 9033248

17. Klam S, Arseneau J, Mansour N, et al. Comparison of endocervical curettage and endocervical brushing. Obstet Gynecol. 2000; 96(1): 90-94, indexed in Pubmed: 10862849.

18. Hoffman MS, Sterghos S, Gordy LW, et al. Evaluation of the cervical canal with the endocervical brush. Obstet Gynecol. 1993; 82(4 Pt 1): 573-577, indexed in Pubmed: 8377985

19. Fine BA, Feinstein Gl, Sabella V. The pre- and postoperative value of endocervical curettage in the detection of cervical intraepithelial neoplasia and invasive cervical cancer. Gynecol Oncol. 1998; 71(1): 46-49, doi: 10.1006/gyno.1998.5120, indexed in Pubmed: 9784317.

20. Massad LS, Einstein MH, Huh WK, et al. 2012 ASCCP Consensus Guidelines Conference. 2012 updated consensus guidelines for the management of abnormal cervical cancer screening tests and cancer precursors. Obstet Gynecol. 2013; 121(4): 829-846, doi: 10.1097/AOG.0b013e3182883a34, indexed in Pubmed: 23635684.

21. Mauney M, Eide D, Sotham J. Rates of condyloma and dysplasia in Papanicolaou smears with and without endocervical cells. Diagn Cytopathol. 1990; 6(1): 18-21, indexed in Pubmed: 2323292.
22. Robertson $\mathrm{JH}$, Woodend B. Negative cytology preceding cervical cancer: causes and prevention. J Clin Pathol. 1993; 46(8): 700-702, indexed in Pubmed: 8408692.

23. Selvaggi SM, Guidos BJ. Endocervical component: is it a determinant of specimen adequacy? Diagn Cytopathol. 2002; 26(1): 53-55, indexed in Pubmed: 11782089.

24. Mitchell H, Medley G. Cytological reporting of cervical abnormalities according to endocervical status. Br J Cancer. 1993; 67(3): 585-588, indexed in Pubmed: 8439508.

25. Mitchell H, Medley G. Influence of endocervical status on the cytologic prediction of cervical intraepithelial neoplasia. Acta Cytol. 1992; 36(6): 875-880, indexed in Pubmed: 1449025.

26. Mitchell HS. Longitudinal analysis of histologic high-grade disease after negative cervical cytology according to endocervical status. Cancer. 2001; 93(4): 237-240, indexed in Pubmed: 11507695.

27. Spaczyński M, Karowicz-Bilinska A, Kedzia W, et al. [Attendance rate in the Polish Cervical Cancer Screening Program in the years 2007-2009]. Ginekol Pol. 2010; 81(9): 655-663, indexed in Pubmed: 20973201.

28. Poynor EA, Barakat RR, Hoskins WJ. Management and follow-up of patients with adenocarcinoma in situ of the uterine cervix. Gynecol Oncol. 1995; 57(2): 158-164, doi: 10.1006/gyno.1995.1118, indexed in Pubmed: 7729727.

29. Wolf JK, Levenback C, Malpica A, et al. Adenocarcinoma in situ of the cervix: significance of cone biopsy margins. Obstet Gynecol. 1996; 88(1): 82-86, doi: 10.1016/0029-7844(96)00083-X, indexed in Pubmed: 8684768

30. Irvin W, Flora S, Andersen W, et al. Endocervical curettage. Does it contribute to the management of patients with abnormal cervical cytology? J Reprod Med. 2004; 49(1): 1-7, indexed in Pubmed: 14976787.

31. Espindola D, Kennedy KA, Fischer EG. Management of abnormal uterine bleeding and the pathology of endometrial hyperplasia. Obstet Gynecol Clin North Am. 2007; 34(4): 717-737, doi: 10.1016/j.ogc.2007.09.001, indexed in Pubmed: 18061866.

32. Munro MG, Critchley HOD, Broder MS, et al. FIGO Working Group on Menstrual Disorders. FIGO classification system (PALM-COEIN) for causes of abnormal uterine bleeding in nongravid women of reproductive age. Int J Gynaecol Obstet. 2011; 113(1): 3-13, doi: 10.1016/j.ijgo.2010.11.011, indexed in Pubmed: 21345435.

33. Boardman LA, Meinz $H$, Steinhoff MM, et al. A randomized trial of the sleeved cytobrush and the endocervical curette. Obstet Gynecol. 2003; 101(3): 426-430, indexed in Pubmed: 12636943. 